\title{
Blood-feeding patterns of Anopheles mosquitoes in a malaria-endemic area of Bangladesh
}

\author{
Kabirul Bashar ${ }^{1 * \dagger}$, Nobuko Tuno ${ }^{2 \dagger}$, Touhid Uddin Ahmed ${ }^{3}$ and Abdul Jabber Howlader ${ }^{1}$
}

\begin{abstract}
Background: Blood-feeding patterns of mosquitoes are crucial for incriminating malaria vectors. However, little information is available on the host preferences of Anopheles mosquitoes in Bangladesh. Therefore, the objective of the present study was to determine the hematophagic tendencies of the anophelines inhabiting a malariaendemic area of Bangladesh.

Methods: Adult Anopheles mosquitoes were collected using light traps (LTS), pyrethrum spray (PS), and human bait (HB) from a malaria-endemic village (Kumari, Bandarban, Bangladesh) during the peak months of malaria transmission (August-September). Enzyme-linked immunosorbent assay (ELISA) and polymerase chain reaction (PCR) were performed to identify the host blood meals of Anopheles mosquitoes.

Results: In total, 2456 female anopheline mosquitoes representing 21 species were collected from the study area. Anopheles vagus Doenitz (35.71\%) was the dominant species followed by An. philippinensis Ludlow (26.67\%) and An. minimus s.l. Theobald (5.78\%). All species were collected by LTs set indoors $(n=1094), 19$ species were from outdoors $(n=784)$, whereas, six by PS $(n=549)$ and four species by HB $(n=29)$. Anopheline species composition significantly differed between every possible combination of the three collection methods $\left(\chi^{2}\right.$ test, $\left.P<0.001\right)$. Host blood meals were successfully detected from 1318 (53.66\%) Anopheles samples belonging to 17 species. Values of the human blood index (HBI) of anophelines collected from indoors and outdoors were $6.96 \%$ and $11.73 \%$, respectively. The highest values of $\mathrm{HBI}$ were found in An. baimai Baimaii (80\%), followed by An. minimus s.l. (43.64\%) and An. annularis Van den Wulp (37.50\%). Anopheles baimai $\left(B_{i}=0.63\right)$ and An. minimus s.l. $\left(B_{i}=0.24\right)$ showed strong relative preferences $\left(B_{i}\right)$ for humans among all hosts (human, bovine, goats/sheep, and others). Anopheles annularis, An. maculatus s.l. Theobald, and An. pallidus Theobald exhibited opportunistic blood-feeding behavior, in that they fed on either humans or animals, depending on whichever was accessible. The remaining 12 species preferred bovines as hosts.
\end{abstract}

Conclusions: The observed high anthropophilic nature of An. baimai, An. minimus s.l., and An. annularis revealed these species to be important malaria vectors in hilly areas of Bangladesh. Higher values of HBI in outdoor-resting mosquitoes indicated that indoor collection alone is not adequate for evaluating malaria transmission in the area.

\section{Background}

Malaria is endemic to Bangladesh (formerly Bengal), and due to the efforts of the nation's Malaria Eradication Program, malaria is now confined to the northeastern border areas of Bangladesh. Thirteen of 64 districts bordering India and Myanmar are severely affected by malaria [1]. Among these, the districts of Chittagong,

\footnotetext{
* Correspondence: bkabirul@gmail.com

† Contributed equally

'Laboratory of Entomology, Department of Zoology, Jahangirnagar

University, Savar, Dhaka 1342, Bangladesh

Full list of author information is available at the end of the article
}

Rangamati, Khagrachari, Bandarban, and Cox's Bazar are hyperendemic, whereas the districts of Kurigram, Sherpur, Mymensingh, Netrakona, Sylhet, Sunamgonj, Moulvibazar, and Hobiganj are prone to low-level epidemics. In 2009, 47 deaths with 63,871 laboratory-confirmed cases and 553,787 clinical cases were reported [2]. Most infections are caused by Plasmodium falciparum in all districts except for Kurigram, where $P$. vivax $(75.07 \%)$ is dominant [3]. The highest incidence of $P$. falciparum (93.16\%) in Bangladesh has been reported from the three hilly districts (Bandarban, Khagrachari, and Rangamati) [4]. The average malaria prevalence in these three

\section{C) Biomed Central}


districts is $11.7 \%$ (Figure 1) [1], and these areas remain highly conducive to malaria due to uncontrolled immigration, political unrest, and hilly terrain.

Seven anopheline species have been incriminated as competent malaria vectors in Bangladesh [5]. Four of these seven species (Anopheles baimai Baimaii, formerly known as $A n$. dirus species D; An. philippinensis Ludlow; An. sundaicus Rodenwaldt; and An. minimus s. 1. Theobald) have been considered the primary vectors [6]. In hilly districts, the principal malaria vectors are An. baimai and An. minimus s.l., whereas An. philippinensis and An. minimus s.l. dominate in flat plane areas of Bangladesh [6]. The other three species, An. aconitus
Doenitz, An. annularis Van der Wulp, and An. vagus Doenitz, transmit malaria during outbreak situations [7-10].

Anophelines exhibit a wide range of host preferences such as humans, livestock, birds, and reptiles [11-13], and the prevalence of malaria is influenced by mosquito host selection [14]. If mosquitoes do not discriminate among host species, the proportion of blood meals attributable to specific hosts would reflect the relative abundance of host animals. Alternatively, certain mammalian species might be more attractive or accessible for specific mosquito species. Such host preferences, especially the degree of anthropophily, would affect the efficacy of

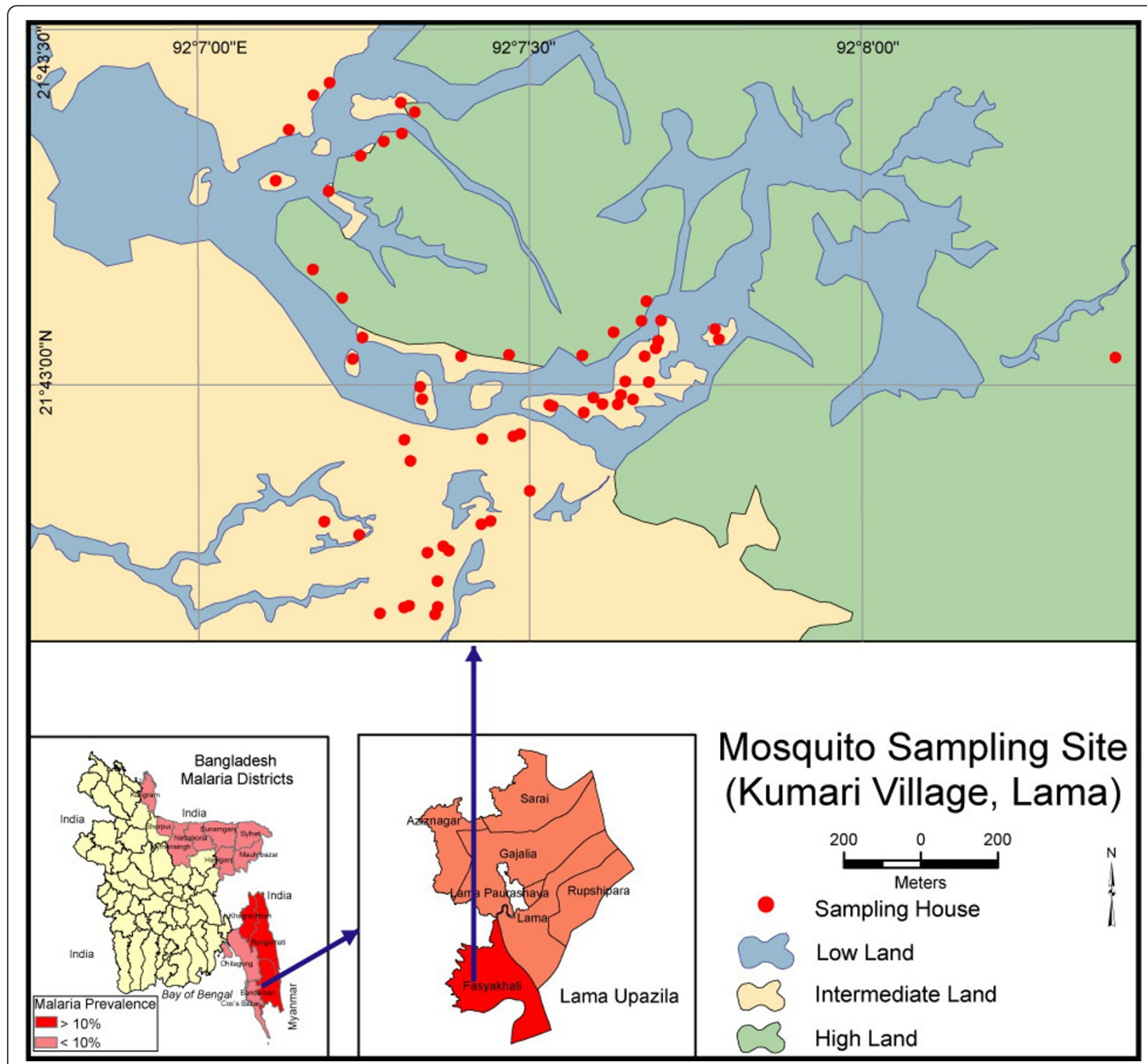

Figure 1 Sampling area in Kumari, Lama, Bangladesh. Low lands = rice field or water bodies, Intermediate lands = foothills, High lands $=$ hilly forest. 
the malaria vector. Climatic, environmental, and socioeconomic factors also influence vector populations by determining feeding behavior and vectorial capacity of malaria transmission [15-17]. Understanding the bloodforaging patterns of insects in the field is tantamount to implicating vectors [18]. However, little information is available regarding the host preferences and blood-feeding behavior of Anopheles species in Bangladesh. Therefore, the present study was conducted to document the hematophagic tendencies of confirmed and suspected malaria vectors in a malaria-endemic area of Bangladesh.

\section{Methods}

\section{Study area}

The study was conducted in the isolated (closest village is $2 \mathrm{~km}$ away), highly malaria-prone village of Kumari (214' $30^{\prime \prime} \mathrm{N}, 92^{\circ} 12^{\prime} 00^{\prime \prime E}$; 26-72 $\mathrm{m}$ above sea level) in Lama Upazila, Bandarban District, Bangladesh (Figure 1 ). The study area is located in a tropical monsoon-type climate zone, with hot and rainy summers and a pronounced dry season during cooler months. The climate is one of the wettest in the world, with a monthly average rainfall of more than $317.8 \mathrm{~mm}$ [19]. Major portions of the study area are vegetated by secondary forest with interspersed rubber plantations. Mosquito breeding sites within the village include a narrow, slow-running stream and many wells, pools, ponds, and rice fields. The village of Lama resides within several hillsides and is inhabited by 1218 individuals (male percentage: 53.94\%) in 137 houses. Most families in the village keep livestock in their compound, including bovines, goats, and sheep. A typical compound consists of a human residence and a shed for animals. The majority of houses are made of mud walls with a tin roof and an opening between the wall and the roof for aeration. Doors and windows are normally kept open until people go to bed. The study village was selected from among several applicant villages because of its high incidence of malaria and because it serves as a typical village in the hilly district, based on its landscape composed of scattered houses, secondary forest, and rubber plantations. We conducted preliminary sampling of malaria vector species within several villages from April to June 2010, after which we focused on Lama, where most of the malaria vector species could be sampled in one village.

\section{Mosquito collections}

The period from May to August has been reported as the peak malaria season in Bangladesh [20]. Mosquitoes were collected from $28^{\text {th }}$ August to $8^{\text {th }}$ September 2010, both indoors and outdoors in 58 selected houses from the study area using light traps (LTs), pyrethrum spray (PS), and human bait (HB) following World Health Organization procedures [21]. Ethical clearance was obtained from Jahangirnagar University, the head of the village, and the office of the Faisha Khali Union Parishod (local government), Lama Upazila, Bandarban. Collectors and individuals serving as human bait were given antimalarial drugs for disease prevention.

\section{Mosquito identification}

Collected mosquitoes were kept in paper cups and brought to the field laboratory for identification. At the laboratory, mosquitoes were anesthetized with chloroform and morphologically identified under stereomicroscopes, within $24 \mathrm{~h}$ after sampling using taxonomic keys [22-26]. After field sampling, mosquitoes were transported to the laboratory at Jahangirnagar University and frozen. All samples were then transported to the ecology laboratory of Kanazawa University for verifying species and blood-meal identification.

\section{Sample preparation and blood-meal analysis}

Collected females Anopheles were prepared for a blood meal test. The abdomen of the mosquitoes was separated from the head and thorax and homogenized in $250 \mu \mathrm{l}$ of phosphate-buffered saline (PBS; pH 7.4). Anophelines were tested for blood meals of humans, bovines, and goats using enzyme-linked immunosorbent assays (ELISAs) as described by Beier et al. [27] with slight modification. All abdomens were soaked in $250 \mu \mathrm{l}$ of PBS before the test, and $50 \mu \mathrm{l}$ was then added to each well of three types (bovine, goat/sheep, human) of ELISA plates, with two replicates per type. The samples were visually judged by comparison with negative and positive samples. If three of three trials were positive, we judged the sample as positive. We also applied molecular methods to samples judged as negative in ELISA. DNA was extracted from residual mosquito abdomens. Briefly, mosquitoes were homogenized in $120 \mu \mathrm{l}$ of warm DNA extraction buffer (DEB: sodium dodecyl sulfate (SDS), 0.5M EDTA, $5 \mathrm{M} \mathrm{NaCl}, 1.0 \mathrm{M}$ Tris buffer $(\mathrm{pH} 8)$ ) and $1.5 \mu \mathrm{l}$ of RNAse $\mathrm{A}$ was added. Then $3 \mu \mathrm{l}$ of proteinase $\mathrm{K}$ was added to each homogenate and incubated at $50^{\circ} \mathrm{C}$ for 60 minutes. After incubation $60 \mu \mathrm{l}$ of each phenol and chloroform were added and centrifuged for 10 minutes. The supernatant was transferred to a tube and $300 \mu$ l of ice-cold 95\% ethanol was added and allowed to precipitate overnight in the $-20^{\circ} \mathrm{C}$ freezer. Samples were then centrifuged for 10 minutes at the highest speed (13000 rpm) and the supernatant was discarded, $300 \mu \mathrm{l}$ of ice-cold $70 \%$ ethanol was then added without disturbing the pellet. Finally, the supernatant was discarded and dried pellets were resuspended in $100 \mu \mathrm{l}$ of TE $\mathrm{pH}$ 7.4. Extracted DNA was diluted in double distilled water at a 1:1000 dilution. PCR was conducted using primers of humans, bovines, dogs, goats/sheep, and pigs as described by Kent and Norris [28]. One microliter of extracted DNA from a single 
mosquito abdomen was applied as a DNA template for a reaction of $20 \mu \mathrm{l}$ using PCR mastermix (GoTaq; Promega KK, Tokyo, Japan). Along with positive and negative controls, $10 \mu \mathrm{l}$ of amplified product was used for electrophoresis in a $2 \%$ agarose gel. To identify the host blood meals, the size of the amplified products was measured under UV lights by comparison with DNA ladder markers. When no DNA was amplified, nested PCR was applied twice using the previous PCR products as the DNA template.

\section{Host census}

We visited all sampling houses to collect information about cases of malaria, the number of family members, and available mammal hosts kept in the compound using standard pretested questionnaires. We used host data to calculate the forage ratio and selection index (see below). Epidemiological information was used for sampling mosquitoes but was not directly applied in the data analysis.

\section{Data analysis}

We compared species composition among the three sampling methods and evaluated the bias in respective species using chi-square $\left(\chi^{2}\right)$ tests with Bonferroni correction. To demonstrate the anthropophilic nature of Anopheles mosquitoes, the proportion of human blood within an entire mosquito blood meal was calculated as the human blood index (HBI). We also calculated the forage ratio $\left(w_{i}\right),[29,30]$ and selection index $\left(B_{i}\right)$ of Manly et al. [31] to quantify host preferences among humans, bovines, goats/sheep, and others. The forage ratio $w_{i}$ for species $i$ was calculated as

$$
w_{i}=\frac{o_{i}}{p_{i}}
$$

where $w_{i}$ is the forage ratio for mosquito species $i, o_{i}$ is the proportion of host species $i$ in the blood meals, and $p_{i}$ is the proportion of host species $i$ available in the environment.

The selection index for species $i$ was calculated as

$$
B_{i}=\frac{w_{i}}{\sum_{i=1}^{n} w_{i}}
$$

Where $B_{i}$ is the selection index for mosquito species $i$, $w_{i}$ is the forage ratio for mosquito species $i$, and $n$ is the number of different types of blood sources available.

Dogs were not considered in the calculations of $w_{i}$ and $B_{i}$ because PCR identified only one dog blood meal among all samples tested. Forage ratios were calculated in two ways: using values of $o_{i}$ and $p_{i}$ from direct counts of animals and using log-transformed data $\left[\log \left(p_{i}+1\right)\right]$ to take into account the fact that animals are not distributed at random in the study area. With $n$ types of host species, values of $1 / n$ of the standardized forage ratio or the selection index $\left(B_{i}\right)$ indicate no preference, those below $1 / n$ indicate relative avoidance, and values above $1 / n$ indicate relative preference of host species $i$. G-tests [31] were conducted to compare these values to the null hypothesis that mosquitoes have no preference for particular hosts. Standard errors and confidence limits were calculated to determine the statistical significance of the forage ratio $\left(w_{i}\right)$ and selection index $\left(B_{i}\right)$. Bonferroni correction [31] was applied for multiple comparisons.

The geographical positions of the sampling houses were determined using handheld GPS (Garmin Oregon 550). ArcView GIS 3.3 and Arc GIS 9.2 software were used for map preparation of the sampling area.

\section{Results}

\section{Species composition}

In total, 2456 female anopheline mosquitoes belonging to 21 species were collected using light traps (LTs), pyrethrum spray (PS), and human bait (HB) (Table 1). All 21 species were collected using LTs set indoors $(\mathrm{n}=$ 1094), and 19 species were collected with outdoor LTs $(\mathrm{n}=784)$. In contrast, only six and four species were collected using PS $(n=549)$ and HB $(n=29)$, respectively (Table 1 ). Mosquito species composition significantly differed between every possible combination of the three collection methods $\left(\chi^{2}\right.$ test, $\left.\mathrm{P}<0.001\right)$. The catches of LT, PS, and HB methods were compared for the dominant nine mosquito species (sample sizes $>50$ ). Anopheles vagus and An. subpictus Grassi were collected more often by PS $\left(\chi^{2}\right.$ test, $\left.\mathrm{P}<0.001\right)$, whereas the seven species (An. vagus, An. philippinensis, An. minimus s.l., An. peditaeniatus Leicester, An. barbirostris Van den Wulp, An. karwari James and An. umbrosus Theobald) were collected more often by LTs $\left(\chi^{2}\right.$ test, $\left.\mathrm{P}<0.05\right)$. Comparisons between LTs and HB indicated that $A n$. philippinensis and $A n$. minimus s.l. were collected more often in $\mathrm{HB}\left(\chi^{2}\right.$ test, $\left.\mathrm{P}<0.05\right)$, whereas five species $(A n$. vagus, An. peditaeniatus, An. barbirostris, An. karwari and $A n$. umbrosus) were collected more frequently with LTs $\left(\chi^{2}\right.$ test, $\left.\mathrm{P}<0.05\right)$; catches of two species did not significantly differ between the two methods. For comparisons between HB and PS, An. philippinensis and An. minimus s.l. were collected more often with $\mathrm{HB}\left(\chi^{2}\right.$ test, $\mathrm{P}<0.001)$, whereas the other six species (An. vagus, $A n$. subpictus, An. peditaeniatus, An. barbirostris, An. aitkenii and $A n$. jamesii) were collected more often with PS $\left(\chi^{2}\right.$ test, $\left.\mathrm{P}<0.01\right)$. Mosquito species composition significantly differed between indoor and outdoor LT collections $\left(\chi^{2}\right.$ test, $\left.\mathrm{P}<0.001\right)$. For the dominant nine $(A n$. vagus, An. philippinensis, An. minimus s.l. An. peditaeniatus, An. barbirostris, An. karwari, An. umbrosus, An. hyrcanus group and $A n$. nigerrimus) species (sample 
Table 1 Anopheles species composition as the proportion collected using light traps (LTs), pyrethrum spray (PS), and human bait (HB) in Kumari, Bangladesh, from August to September 2010

\begin{tabular}{|c|c|c|c|c|c|c|c|c|c|}
\hline \multirow{3}{*}{ Species } & \multirow{3}{*}{$\begin{array}{c}\text { Method } \\
\begin{array}{c}\mathrm{N}= \\
2456\end{array}\end{array}$} & \multicolumn{2}{|r|}{ LT } & \multirow{2}{*}{\multicolumn{2}{|c|}{$\chi 2^{*}$}} & \multirow[t]{2}{*}{ HB } & \multirow{2}{*}{\multicolumn{2}{|c|}{$\chi^{2}$}} & \multirow[b]{3}{*}{ PS vs. HB } \\
\hline & & Indoors & Outdoors & & & & & & \\
\hline & & $\begin{array}{c}N= \\
1094\end{array}$ & $\begin{array}{l}N= \\
784\end{array}$ & In vs. Out & $\begin{array}{l}N= \\
549\end{array}$ & $\begin{array}{c}\mathrm{N}= \\
29\end{array}$ & LT vs. PS & LT vs. HB & \\
\hline An. vagus & 879 & 0.182 & 0.212 & ns & 0.936 & & $<0.001$ & $<0.001$ & $<0.001$ \\
\hline An. philippinensis & 655 & 0.338 & 0.335 & ns & & 0.759 & $<0.001$ & $<0.001$ & $<0.001$ \\
\hline An. minimus s.l. & 142 & 0.081 & 0.065 & ns & & 0.069 & $<0.05$ & 0.022 & $<0.001$ \\
\hline An. peditaeniatus & 139 & 0.094 & 0.045 & $<0.001$ & 0.002 & & $<0.001$ & 0.009 & $<0.001$ \\
\hline An. barbirostris & 130 & 0.059 & 0.083 & ns & 0.002 & & $<0.001$ & 0.014 & $<0.001$ \\
\hline An. karwari & 128 & 0.073 & 0.061 & ns & & & $<0.05$ & 0.011 & $<0.001$ \\
\hline An. umbrosus & 128 & 0.032 & 0.119 & $<0.001$ & & & $<0.05$ & 0.011 & $<0.001$ \\
\hline An. hyrcanus group & 52 & 0.031 & 0.023 & ns & & & ns & ns & 0.004 \\
\hline An. nigerrimus & 52 & 0.045 & 0.004 & $<0.001$ & & & ns & ns & 0.004 \\
\hline An. subpictus & 40 & 0.005 & 0.005 & & 0.056 & & & & \\
\hline An. pallidus & 24 & 0.011 & 0.015 & & & & & & \\
\hline An. baimai & 23 & 0.015 & 0.005 & & & 0.103 & & & \\
\hline An. maculatus s.l. & 22 & 0.015 & 0.008 & & & & & & \\
\hline An. annularis & 18 & 0.005 & 0.013 & & & 0.069 & & & \\
\hline An. jeyporiensis & 7 & 0.005 & 0.003 & & & & & & \\
\hline An. kochi & 5 & 0.003 & 0.003 & & & & & & \\
\hline An. aitkenii & 4 & 0.002 & 0.001 & & 0.002 & & & & \\
\hline An. jamesii & 3 & 0.001 & 0.001 & & 0.002 & & & & \\
\hline An. tessellatus & 2 & 0.002 & & & & & & & \\
\hline An. varuna & 2 & 0.002 & & & & & & & \\
\hline An. fluviatiles & 1 & 0.001 & & & & & & & \\
\hline $\begin{array}{l}\text { Total } \\
\end{array}$ & & 1 & 1 & & 1 & 1 & & & \\
\hline
\end{tabular}

${ }^{*} \chi 2$ tests were applied for the dominant species $(\mathrm{n}>50)$ to compare the proportions of indoor vs outdoor LT catches as well as LT vs. PS, PS vs. HB, and HB vs. $\mathrm{LT} ; \mathrm{ns}=$ not significant.

sizes were more than 50 for LT catches), An. peditaeniatus and $A n$. nigerrimus Giles were captured more often via indoor LTs, whereas An. umbrosus was caught more frequently in outdoor LTs $\left(\chi^{2}\right.$ test, $\mathrm{P}<0.001$; Table 1).

\section{Feeding status and blood-meal host identification}

Mosquito feeding status was visually classified as unfed (UF), fed (F), half-gravid (HG), or gravid (G). The highest percentage of specimens was UF (49.59\%), followed by $\mathrm{F}(30.46 \%)$, HG $(17.59 \%)$, and G $(2.36 \%)$. We were able to successfully identify the host animals of the majority of F (96.79\%) and HG (95.60\%) mosquito blood meals. A sizable percentage (10.67\%) of blood meals visually categorized as UF reacted as blood-meal positive. The host blood meals of 50 engorged (F, HG, and G) mosquitoes were not identified (Table 2).

\section{Potential host composition}

During the sampling period, we observed 403 humans, 156 bovines, 98 goats and sheep, and 36 dogs in the sampled houses.

\section{Blood feeding of anophelines collected indoors and} outdoors

Seventeen Anopheles species of 21 tested positive for blood meals. The total numbers of tested blood meals from indoor and outdoor collections were 1647 and 809, respectively. Of 1318 mosquito blood meals, 977 $(74.13 \%)$ were collected indoors, and the remainder was collected outdoors (Table 3). The highest human blood index (HBI) was found in An. baimai (in: 66.7\%, $\mathrm{n}=3$; out: $100 \%, \mathrm{n}=2$ ), followed by An. minimus s.l. (in: $47.06 \%, \mathrm{n}=34$; out: $38.1 \%, \mathrm{n}=21$ ), An. annularis (in: $50 \%, \mathrm{n}=4$; out: $33.33 \%, \mathrm{n}=3$ ), and An. pallidus Theobald (in: $37.5 \%, \mathrm{n}=8$; out: $50 \%, \mathrm{n}=4)$. In five taxa $(A n$. hyrcanus group, An. jamesii Theobald, An. maculatus s. 1. James, An. peditaeniatus, and An. subpictus), human blood was not detected outdoors but was detected in indoor collections. Lone species (An. umbrosus) collected from indoors found 0\% HBI. The highest HBI was observed in An. baimai $(80 \%, \mathrm{n}=5)$, followed by An. minimus s.l. (43.64\%, $\mathrm{n}=55)$, An. annularis $(37.5 \%$, $\mathrm{n}=7$ ), and An. pallidus (33.33\%, $\mathrm{n}=12$ ) of the $17 \mathrm{col}-$ lected species. The average HBI values for indoor and 
outdoor collections were $6.96 \%$ and $11.73 \%$, respectively (Table 3). None of the hosts were identified for four species: An. fluviatiles James $(\mathrm{n}=1)$, An. jeyporiensis James $(\mathrm{n}=7), A n$. tessellates Theobald $(\mathrm{n}=2)$, and $A n$. varuna Iyengar $(\mathrm{n}=2)$.

\section{Multiple host feeding}

Multiple host feeding was only detected in mosquitoes when they took blood from different types of hosts, which occurred in 74 individuals (5.61\%). The observed combinations were human and goat $(\mathrm{n}=37)$, human and bovine $(\mathrm{n}=22)$, and human, bovine, and goat $(\mathrm{n}=$ 13). The highest number of multiple feedings was detected in An. vagus $(62 \%, \mathrm{n}=46)$.

\section{Host preference}

The forage ratio $\left(w_{i}\right)$, host selection index $\left(B_{i}\right)$, and Gtest values for 1318 individuals (2456 tested) from 14 anopheline taxa are presented in Table 4 . The bovine category was the most preferred animal, followed by goats/sheep and humans (Table 4). Relative preferences for humans occurred in An. baimai $\left(B_{i}=0.61\right)$ and $A n$. minimus s.l. $\left(B_{i}=0.24\right)$. Anopheles annularis, An. maculatus s.l., and An. pallidus exhibited opportunistic blood-feeding behavior, in that they preferred to feed on accessible hosts, either human or animal. The remainder of species showed relative preferences for bovine hosts. For three species (An. annularis, An. maculatus s.l., and An. pallidus), the use of raw or log-transformed data to obtain G-test values for host abundance produced different results, whereas for the other 11 anopheline taxa, the two methods produced similar results in terms of preferred hosts (Table 4).

\section{Discussion}

The present study confirmed that anopheline species composition can vary with different sampling methods. Only four species (An. philippinensis, An. minimus s.l., An. baimai, and An. annularis) were collected using human bait (HB), the most vital method for discriminating anthropophilic species. Anopheles baimai and An. annularis were dominant only in HB collections. Light traps (LTs) captured all species and can be considered the most neutral method for collecting mosquitoes. However, the differences between indoor or outdoor LT
Table 3 Human blood index (HBI) of Anopheles species collected indoors and outdoors

\begin{tabular}{lccccc}
\hline Species & \multicolumn{2}{c}{$\begin{array}{c}\text { Indoor } \\
\text { collections }\end{array}$} & \multicolumn{2}{c}{$\begin{array}{c}\text { Outdoor } \\
\text { collections }\end{array}$} & Overall HBI \\
\cline { 2 - 5 } & $\mathbf{N}$ & HBI & N & HBI & \\
\cline { 2 - 4 } An. aitkenii & 1 & 0 & & & 0 \\
An. annularis & 4 & 50 & 3 & 33.33 & 37.5 \\
An. baimai & 3 & 66.67 & 2 & 100 & 80 \\
An. barbirostris & 31 & 3.23 & 31 & 6.45 & 4.62 \\
An. hyrcanus group & 16 & 6.25 & 7 & 0 & 4.35 \\
An. jamesii & 2 & 50 & & & 33.33 \\
An. karwari & 41 & 2.44 & 16 & 6.25 & 3.39 \\
An. kochi & 1 & 0 & & & 0 \\
An. maculatus s.l. & 10 & 40 & 1 & 0 & 26.67 \\
An. minimus s.l. & 34 & 47.06 & 21 & 38.1 & 43.64 \\
An. nigerrimus & 28 & 0 & 1 & 0 & 0 \\
An. pallidus & 8 & 37.5 & 4 & 50 & 33.33 \\
An. peditaeniatus & 63 & 7.94 & 10 & 0 & 6.41 \\
An. philippinensis & 134 & 19.4 & 109 & 19.27 & 18.43 \\
An. subpictus & 27 & 14.81 & & & 12.12 \\
An. umbrosus & 24 & 0 & 81 & 6.17 & 4.55 \\
An. vagus & 550 & 10.55 & 55 & 25.45 & 10.29 \\
\hline Total & 977 & 6.96 & 341 & 11.73 & \\
\hline & & & & & 0 \\
\hline
\end{tabular}

catches indicate that attention must be paid to where LTs are set. Six species were collected using pyrethrum spray (PS); however, more than 93\% were An. vagus. Mosquito species composition differed between LT and PS collection methods, and only An. vagus and An. subpictus were collected more often by PS. These results verified the effectiveness of $\mathrm{HB}$, which only collects anthropophilic species, and demonstrated that the application of PS is not particularly useful for collecting anthropophilic species.

The prevalence of malaria is influenced by host preferences of Anopheles species, but little information is available on such preferences in Bangladesh [32]. In nature, the expression of host preference (selection of host) by a mosquito may depend on several extrinsic or intrinsic factors $[33,34]$. In the present study, the HBI values of mosquitoes collected indoors and outdoors were $6.96 \%$ and $11.73 \%$, respectively. The higher $\mathrm{HBI}$ in outdoor-collected mosquitoes suggests two possibilities: people may be bitten more frequently outdoors, or

Table 2 Number of blood meals identified and their feeding status

\begin{tabular}{llll}
\hline Feeding status & Number of individuals (\%) & Blood Meal Identified (\%) & BM not identified (\%) \\
\hline Blood-fed & $748(30.46)$ & $724(96.79)$ & $24(3.21)$ \\
Gravid & $58(2.36)$ & $51(87.93)$ & $7(12.07)$ \\
Half-gravid & $432(17.59)$ & $413(95.60)$ & $19(4.40)$ \\
Unfed & $1218(49.59)$ & $130(10.67)$ & $50(3.65)$ \\
\hline Total & $2456(100.00)$ & $1318(53.66)$ & \\
\hline
\end{tabular}


Table 4 Host selection index $\left(B_{i}\right)$ of Anopheles species in Kumari, Bangladesh

\begin{tabular}{|c|c|c|c|c|c|c|c|}
\hline \multirow[t]{2}{*}{ Species } & \multirow[t]{2}{*}{ Host data } & \multicolumn{4}{|c|}{ Host selection index $\left(B_{i}\right)$} & \multirow[t]{2}{*}{ G-test value } & \multirow[t]{2}{*}{ P-value } \\
\hline & & Human & Bovine & Goat \& Sheep & Others & & \\
\hline \multirow[t]{2}{*}{ An. annularis } & Raw & 0.16 & $0.41^{*}$ & $0.43^{*}$ & 0 & 8.77 & 0.07 \\
\hline & Log-transformed & $0.33^{*}$ & $0.39^{*}$ & $0.28^{*}$ & 0 & 7.63 & 0.11 \\
\hline \multirow[t]{2}{*}{ An. baimai } & Raw & $0.61^{*}$ & $0.39^{*}$ & 0 & 0 & 6.10 & 0.19 \\
\hline & Log-transformed & $0.77^{*}$ & $0.23^{*}$ & 0 & 0 & 9.62 & 0.05 \\
\hline \multirow[t]{2}{*}{ An. barbirostris } & Raw & 0.02 & $0.89^{*}$ & 0.1 & 0 & 187.13 & $<0.01$ \\
\hline & Log-transformed & 0.04 & $0.89^{*}$ & 0.07 & 0 & 153.70 & $<0.01$ \\
\hline \multirow[t]{2}{*}{ An. hyrcanus group } & Raw & 0.02 & $0.91^{*}$ & 0.07 & 0 & 68.68 & $<0.01$ \\
\hline & Log-transformed & 0.04 & $0.92^{*}$ & 0.05 & 0 & 57.06 & $<0.01$ \\
\hline \multirow[t]{2}{*}{ An. karwari } & Raw & 0.01 & $0.92^{*}$ & 0.05 & 0.01 & 172.48 & $<0.01$ \\
\hline & Log-transformed & 0.03 & $0.92^{*}$ & 0.04 & 0.01 & 143.38 & $<0.01$ \\
\hline \multirow[t]{2}{*}{ An. maculatus s.l. } & Raw & 0.1 & $0.33^{*}$ & $0.53^{*}$ & 0.03 & 13.76 & 0.01 \\
\hline & Log-transformed & $0.23^{*}$ & $0.34^{*}$ & $0.37^{*}$ & 0.06 & 9.35 & 0.05 \\
\hline \multirow[t]{2}{*}{ An. minimus s.l. } & Raw & $0.22^{*}$ & $0.67^{*}$ & 0.11 & 0 & 67.85 & $<0.01$ \\
\hline & Log-transformed & $0.39^{*}$ & $0.54^{*}$ & 0.06 & 0 & 73.23 & $<0.01$ \\
\hline \multirow[t]{2}{*}{ An. nigerrimus } & Raw & 0 & $1.00^{*}$ & 0 & 0 & 108.45 & $<0.01$ \\
\hline & Log-transformed & 0 & $1.00^{*}$ & 0 & 0 & 92.77 & $<0.01$ \\
\hline \multirow[t]{2}{*}{ An. pallidus } & Raw & 0.15 & $0.56^{*}$ & $0.25^{*}$ & 0.04 & 11.90 & 0.02 \\
\hline & Log-transformed & $0.29^{*}$ & $0.49^{*}$ & 0.15 & 0.06 & 11.26 & 0.02 \\
\hline \multirow[t]{2}{*}{ An. peditaeniatus } & Raw & 0.03 & $0.89^{*}$ & 0.08 & 0.01 & 205.88 & $<0.01$ \\
\hline & Log-transformed & 0.05 & $0.88^{*}$ & 0.06 & 0.01 & 169.71 & $<0.01$ \\
\hline \multirow[t]{2}{*}{ An. philippinensis } & Raw & 0.08 & $0.84^{*}$ & 0.07 & 0.01 & 479.22 & $<0.01$ \\
\hline & Log-transformed & 0.16 & $0.77^{*}$ & 0.04 & 0.02 & 415.25 & $<0.01$ \\
\hline \multirow[t]{2}{*}{ An. subpictus } & Raw & 0.05 & $0.84^{*}$ & 0.05 & 0.05 & 60.31 & $<0.01$ \\
\hline & Log- transformed & 0.1 & $0.78^{*}$ & 0.03 & 0.08 & 51.46 & $<0.01$ \\
\hline \multirow[t]{2}{*}{ An. umbrosus } & Raw & 0.02 & $0.82^{*}$ & 0.17 & 0 & 297.72 & $<0.01$ \\
\hline & Log-transformed & 0.04 & $0.84^{*}$ & 0.12 & 0 & 237.17 & $<0.01$ \\
\hline \multirow[t]{2}{*}{ An. vagus } & Raw & 0.04 & $0.81^{*}$ & 0.12 & 0.03 & 1393.67 & $<0.01$ \\
\hline & Log-transformed & 0.09 & $0.79^{*}$ & 0.08 & 0.05 & 1132.35 & $<0.01$ \\
\hline
\end{tabular}

Threshold level for $B_{i}=0.2 ;{ }^{*}$ indicates the preferred host.

Values of $B_{i}$ were not calculated for those species for which less than five individuals were captured.

indoor-biting mosquitoes do not remain inside and instead exit at night. Both possibilities may indicate that mosquitoes are becoming exophagic or that exophagic traits are favored by insecticidal pressure of bed nets. Anopheles baimai, an efficient malaria vector in Bangladesh, usually rests and bites humans outdoors, even though it is highly anthropophilic $[6,35,36]$. The higher HBI in outdoor-collected anophelines along with the higher outdoor-biting tendency of malaria vectors in Bangladesh $[6,35]$ indicate that bed nets or other devices used indoors may not provide enough protection from vectors.

Anopheles species incriminated as malaria vectors exhibit preferences for humans [34]. Ramsay et al. [37] reported a substantial preference for human blood by $A n$. minimus, which was supported in part by Toumanoff and $\mathrm{Hu}$ [38] in Vietnam. However, this species (collected outdoors) exhibited a low HBI in the Philippines
[39] and India [40]. We found that both bovine $\left(B_{i}=\right.$ $0.54)$ and human $\left(B_{i}=0.39\right)$ hosts were preferred by $A n$. minimus s.l. in Kumari, Bangladesh.

Anopheles maculatus has been reported as an important malaria vector in the Malay Peninsula but is considered less important in Bangladesh [6], Assam, Borneo [37,41], and the Philippines [39]. Wharton [42] reported that the Malayan An. maculatus feeds uniformly on animals, although it exhibits a slight preference for humans even when animals are accessible. We found that both humans $\left(B_{i}=0.23\right)$ and bovines $\left(B_{i}=0.34\right)$ were the preferred hosts of this species. Similar results were reported in Hong Kong [43], whereas An. maculatus appears to feed largely on bovine hosts in the Philippines [39]. Thus, An. maculatus feeds on either bovine or human hosts, whichever is more abundant or accessible.

A higher value of the HBI in an Anopheles species indicates that it can function as a malaria vector [36]. In 
our study, higher values of HBI were found in An. baimai (80\%), An. minimus s.l. (43.64\%), and An. annularis (37.50\%). These three species have been recognized as malaria vectors in Bangladesh, and the former two species play a main role in transmitting malaria in hilly and forested areas $[6,35,36]$. Very low to negligible values of HBI were found in An. kochi, An. nigerrimus, An. aitkenii, An. karwari, the An. hyrcanus group, An. umbrosus, and An. barbirostris. Recently, Alam et al. [20] reported a high malaria infection rate for An. karwari, An. barbirostris, An. nigerrimus, and An. subpictus in Bangladesh. In contrast, these species are generally zoophilic and prefer to feed on bovine blood [44]. In the present study, we found low HBI in An. karwari, An. barbirostris, and An. nigerrimus. These species are considered to be non-vectors, with the exception of An. subpictus, on the Indian subcontinent [41], which is in agreement with our observed HBI values for these species. Some non-vector species may be overestimated as malaria vectors due to the methods used [20]. For example, using the entire mosquito body in ELISA can lead to over evaluation of vectors because Plasmodium species in human blood within mosquitoes are more likely to be detected. It is essential to check for Plasmodium within the upper parts of the mosquito body (thorax and head), and an even more reliable method is dissection because blood is often dispersed throughout the mosquito body and not only in the abdomen.

The densities of potential hosts in the study area must be measured to obtain a better understanding of mosquito host preferences [45]. The selection index $\left(B_{i}\right)$ enables the evaluation of mosquito host preferences with consideration of environmental conditions. A strongly anthropophilic mosquito species would only use humans as preferred hosts, whereas an opportunistic species would prefer more than one host. The value of $B_{i}$ for a particular mosquito species quantifies the intensity of preference, and the number of preferred hosts is a measure of the opportunistic behavior. Anopheles minimus s.l., An. annularis, An. maculatus s.l., and An. pallidus showed opportunistic blood-feeding behavior, indicating that they chose either human or bovine hosts depending on conditions. The other species exhibited clear preferences for bovine hosts. Therefore, the selection index $\left(B_{i}\right)$ results demonstrated that most of the mosquito species preferred bovines and goats as their hosts but not humans. An accurate host population estimation would be rather difficult for estimating the forage ratio. However, forage ratios are more powerful indicators for examining mosquito host blood-feeding preferences compared to other specialized indices [46]. These ratios may be used to compare the feeding preferences of various mosquito species in different areas.
Anopheles annularis and An. vagus are zoophilic, exophilic and exophagic in nature; however, they have been considered malaria vectors in India [41]. These two species were identified as vectors during epidemics in the floodplain areas of Bangladesh. They may have been implicated perhaps due to the low availability of nonhuman mammalian hosts $[9,10]$. Using gel-diffusion methods, a blood-meal analysis of several mosquito species in Dhaka, including three anophelines, indicated that $A n$. vagus and An. barbirostris were highly zoophilic [32], which is in accordance with our results.

We identified a considerable proportion $(5.61 \%)$ of multiple blood meals, a majority of which had been taken from humans and goats. We hypothesize that this combination was particularly frequent because goat shelters are, in many cases, located close to human sleeping rooms. The highest proportion of mixed blood meals occurred in An. vagus, which was collected indoors using PS. Multiple blood-feeding probably occurred due to disturbances or climatic factors [47]. Multiple bloodfeeding is common during a single gonotrophic cycle among mosquitoes, and its epidemiological importance is controversial $[47,48]$. The loss of sporozoites by biting nonhuman animals during mixed feeding could be important in malaria control.

\section{Conclusions}

We studied the blood-feeding patterns of Anopheles mosquitoes in a malaria-endemic area of Bangladesh using three sampling methods. We demonstrated that An. baimai, An. minimus s.l., An. annularis, An. jamesii, An. maculatus s.l., and An. pallidus are more or less anthropophilic, whereas most of the other species are zoophilic. The forage ratio $\left(w_{i}\right)$ and host selection index $\left(B_{i}\right)$ allows the prediction of future changes in mosquito host preference in accordance with the availability of host animal abundance. Mosquito species composition was methodology-specific, and LT sampling serves as a neutral reflection of the relative abundance of fauna. In contrast, human-bait and indoor spray catches are only composed of anthropophilic and endophagic species, respectively. Preliminary surveys using the proper sampling methods are crucial for identifying malaria vectors in Bangladesh.

\section{Acknowledgements}

We thank KMZ Rahman, HM Al-Amin, Md. Selim Reza, and Sagorica for help during fieldwork. Special thanks go to NP Maheswary for a critical review of the manuscript. We also thank K. Hasan Mahmud and M. Rezaul Karim for valuable suggestions and help with data analysis. We acknowledge the Laboratory of Ecology of Kanazawa University, Japan, for providing technical and laboratory space for the blood-meal analysis. This work was partially supported by a RONPAKU fellowship from the Japan Society for the Promotion of Science (JSPS). 


\section{Author details}

'Laboratory of Entomology, Department of Zoology, Jahangirnagar University, Savar, Dhaka 1342, Bangladesh. '2Laboratory of Ecology, Faculty of Natural Science and Technology, Kanazawa University, Kanazawa, Japan. ${ }^{3}$ Institute of Epidemiology, Disease Control \& Research (IEDCR), Mohakhali, Dhaka-1212, Bangladesh.

\section{Authors' contributions}

TN designed the study. KB, TN, and TUA conducted the fieldwork. KB performed the ELISA and PCR assay of mosquito blood meals. KB, TN, TUA, and $\mathrm{AJH}$ collaborated in writing the manuscript. All authors have read and approved the final manuscript.

\section{Competing interests}

The authors declare that they have no competing interests.

Received: 14 October 2011 Accepted: 15 February 2012

Published: 15 February 2012

\section{References}

1. Haque U, Ahmed SM, Hossain S, Huda M, Hossain A, Alam MS, Mondal D, Khan WA, Khalequzzaman M, Haque R: Malaria prevalence in endemic districts of Bangladesh. PLOS ONE 2009, 4:e6737.

2. World Health Organization: World malaria report 2010 Geneva; 2010.

3. Health report of Bangladesh 2010 Director General of Health, Bangladesh government, Dhaka; 2010.

4. Van den Broek IV, van der Wardt S, Talukder L, Chakma S, Brockman A, Nair S, Anderson TC: Drug resistance in Plasmodium falciparum from the Chittagong Hill Tracts, Bangladesh. Trop Med Int Health 2004, 9(6):680-687.

5. Ahmed TU: Checklist of the mosquitoes of Bangladesh. Mosq Syst 1987, 19:187-200.

6. Elias $M$, Dewan ZAR, Ahmed R: Vectors of malaria in Bangladesh. J Prev Social Med 1982, 1:20-28.

7. Sharma VP: Re-emergence of malaria in India. Indian J Med Res 1996 , 103:26-45.

8. Maheswary NP, Habib MA, Elias M: Incrimination of Anopheles aconitus Donitz as a vector of epidemic malaria in Bangladesh. SE Asian J Trop Med 1992, 23:798-801.

9. Maheswary NP, Khan Z, Molla FR, Haq MI: Incrimination of Anopheles annularis van der Wulp-1854 as an epidemic malaria vector in Bangladesh. SE Asian J Trop Med 1993, 24:776-778.

10. Maheswary NP, Majumdar S, Chowdhury AR, Faruque MS, Montanari RM: Incrimination of Anopheles vagus Donitz, 1902 as an epidemic malaria vector in Bangladesh. Indian J Malariol 1994, 31:35-38.

11. Irby WS, Apperson CS: Hosts of mosquitoes in the Coastal Plain of North Carolina. J Med Entomol 1988, 25:85-93.

12. Nanda N, Joshi H, Subbarao SK, Yadav RS, Shukla RP, Dua VK, Sharma VP: Anopheles fluviatilis complex: host feeding patterns of species $\mathrm{S}, \mathrm{T}$ and U. J Am Mosa Control Assoc 1996, 12:147-149.

13. Subbarao SK: Anopheline species complexes in South-East Asia. WHO Tec Pub 1998, 18:82.

14. Burkot TR: Non-random host selection by anopheline mosquitoes. Parasitol Today 1988, 4:156-162

15. Bouma MJ, Dye C, van der Kaay HJ: Falciparum malaria and climate change in the northwest frontier province of Pakistan. Am J Trop Med Hyg 1996, 55:131-137.

16. Hu H, Singhasivanon P, Salazar NP, Thimasarn K, Li X, Wu Y, Yang H, Zhu D, Supavej $S$, Looarecsuwan $S$ : Factors influencing malaria endemicity in Yunnan Province, PR. China (Analysis of spatial pattern by GIS). SE Asian J Trop Med 1998, 29:191-200.

17. Mouchet J, Manguin S, Sircoulon J, Laventure S, Faye O, Onapa AW, Carnebale P, Julvez J, Fontenille D: Evolution of malaria in Africa for the past 40 years: impact of climate and human factors. J Am Mosq Control Assoc 1998, 14:121-130

18. Chaves LF, Hernandez MJ, Dobson AP, Pascual M: Sources and sinks: revisiting the criteria for identifying reservoirs for American cutaneous leishmaniasis. Trends Parasitol 2007, 23:311-316.

19. Banglapedia: National Encyclopedia of Bangladesh. 2010.

20. Alam MS, Khan MGM, Chaudhury N, Deloer S, Nazib F, Bangali AM, Haque R: Prevalence of anopheline species and their Plasmodium infection status in epidemic-prone border areas of Bangladesh. Malar J 2010, 9:15.

21. World Health Organization: Manual on practical entomology in malaria. Part II: Methods and techniques. Division of malaria and other parasitic diseases 1975.

22. Barraud PJ: The fauna of British India, including Ceylon and Burma, Diptera, Vol. 5, Family-Culicidae. Tribes Megarhinini and Culicini Taylor and Francis, London; 1934

23. Bram RM: Contribution to the mosquito fauna to South-East Asia, II. The genus Culex in Thailand (Diptera; Culicidae). Contrib Am Entomol Inst 1967, 2(1):1-296.

24. Christophers SR: The fauna of British India, including Ceylon and Burma. Diptera 4. Family Culicidae. Tribe Anopheline Taylor \& Francis, London; 1933.

25. Puri IM: Synoptic table for the identification of the anopheline mosquitoes of India. 5 edition. Health Bull. No. 10. Malaria Bureau, Govt India Press; 1960.

26. Harrison BA, Scanlon JE: Medical entomology studies-II. The subgenus Anopheles in Thailand. Contrib Am Entomol Inst 1975, 12:1-307.

27. Beier JC, Perkins PV, Wirtz RZ, Koros J, Diggs D, Garam TPI, Koech DK: Blood meal identification by direct enzyme-linked immunosorbent assay (ELISA), tested on Anopheles (Diptera: Culicidae) in Kenya. J Med Entomol 1988, 24:146-150.

28. Kent R, Norris D: Identification of mammalian blood meals in mosquitoes by a multiplexed polymerase chain reaction targeting cytochrome B. Am J Trop Med Hyg 2005, 73:336-342.

29. Hess $\mathrm{AD}$, Hayes $\mathrm{RO}$, Tempelis $\mathrm{CH}$ : The use of the forage ratio technique in mosquito host preference studies. Mosq News 1968, 28:386-389.

30. Savage RE: The relation between the feeding of the herring off the east coast of England and the plankton of the surrounding waters. Fishery Investigation, Ministry of Agriculture, Food and Fisheries 1931, Series 212:188.

31. Manly BFJ, MCDonald LL, Thomas DL: Resource selection by animals. Statistical design and analysis for field studies London, Chapman and Hall; 1993.

32. Ifteara KS, Taleb MA, Ahmed TU: Host preference of common mosquitoes in different habitats. Bangladesh J Entomol 1998, 8(1\&2):59-67.

33. Garret-Jones C, Boreham PFL, Pant CP: Feeding habits of anophelines (Diptera: Culicidae) in 1971-78, with reference to the human blood index: a review. Bull Entomol Res 1980, 70:165-185.

34. Bruce-Chwatt $L$, Gockel CW: A study of the blood-feeding patterns of Anopheles mosquitoes through precipitin tests. WHO Bull 1960, 22:685-720.

35. Rosenberg R, Mahesawary NP: Forest malaria in Bangladesh II. Transmission by Anopheles dirus. Am J Trop Med Hyg 1982, 31:183-191.

36. Khan AQ, Talibi SA: Epidemiological assessment of malaria transmission in an endemic area of East Pakistan \& significance of congenital immunity. WHO Bull 1972, 46:783-792.

37. Ramsay CG, Chandra SN, Lamprell BA: A record of an investigation to determine the androphilic indices of certain anopheline mosquitoes collected on the estates in Assam and Northern Bengal. Rec Mal Sur India 1936, 6:49-61.

38. Toumanoff C, Hu SMK: Sur le comportement trophique de I'A. hyrcanus var. sinensis. Bull Soc Pathol Exot 1936, 28:832-834.

39. Laurel AG: Feeding activities of some Philippine Anopheles. Rev Filipina Med Farm 1934, 25:286-297.

40. Muirhead-Thomson RC: Studies on the behaviour of Anopheles minimus. Part III. The influence of water temperature on the choice and suitability of the breeding place. J Malar Inst India 1940, 3:323-348.

41. Rao TR: The anophelines of India Malaria Research Center (ICMR). New Delhi, India; 1984, 518, Revised edition.

42. Wharton RH: The habit of adult mosquitoes in Malaya. III. Feeding preferences of anophelines. Ann Trop Med Parasitol 1953, 47:272-284

43. Jackson RB: A review of investigations of the habits and pathogenicities of the common anophelines of Hong Kong. Trans R Soc Trop Med Hyg 1951, 45(1):91-101

44. Sinka ME, Michael J, Bangs MJ, Manguin S, Chareonviriyaphap T, Patil AP, Temperley WH, Gething PW, Elyazar IRF, Caroline W, Kabaria CW, Harbach RE, Hay SI: The dominant Anopheles vectors of human malaria in the Asia-Pacific region: occurrence data, distribution maps and bionomic précis. Parasit Vectors 2011, 4:89.

45. Hasegawa M, Tuno N, Yen NT, Nam VS, Takagi M: Influence of the distribution of host species on adult abundance of Japanese encephalitis vectors-Culex vishnui subgroup and Culex gelidus-in a rice- 
cultivating village in Northern Vietnam. Am J Trop Med Hyg 2008, 78(1):159-168.

46. Kay BH, Boreham PFL, Edman JD: Application of the "feeding index" concept to studies of mosquito host-feeding patterns. Mosq News 1979, 39:68-72.

47. Hadis M, Lulu M, Makonnen Y, Asfaw T: Host choice by indoor resting Anopheles arabiensis in Ethiopia. Trans R Soc Trop Med Hyg 1997, 91:376-378.

48. Burkot TR, Graves PM, Paru R, Lagog M: Mixed blood feeding by the malaria vectors in the Anopheles punctulatus complex (Diptera: Culicidae). J Med Ent 1988, 25:205-213.

doi:10.1186/1756-3305-5-39

Cite this article as: Bashar et al:: Blood-feeding patterns of Anopheles mosquitoes in a malaria-endemic area of Bangladesh. Parasites \& Vectors 2012 5:39.

\section{Submit your next manuscript to BioMed Central} and take full advantage of:

- Convenient online submission

- Thorough peer review

- No space constraints or color figure charges

- Immediate publication on acceptance

- Inclusion in PubMed, CAS, Scopus and Google Scholar

- Research which is freely available for redistribution

Submit your manuscript at www.biomedcentral.com/submit 